\title{
Locus Ceruleus Control of State-Dependent Gene Expression
}

\author{
Chiara Cirelli and Giulio Tononi \\ Department of Psychiatry, University of Wisconsin, Madison, Madison, Wisconsin 53719
}

\begin{abstract}
Wakefulness and sleep are accompanied by changes in behavior and neural activity, as well as by the upregulation of different functional categories of genes. However, the mechanisms responsible for such state-dependent changes in gene expression are unknown. Here we investigate to what extent state-dependent changes in gene expression depend on the central noradrenergic (NA) system, which is active in wakefulness and reduces its firing during sleep. We measured the levels of $\sim 5000$ transcripts expressed in the cerebral cortex of control rats and in rats pretreated with DSP-4 [ $N$-(2-chloroethyl)- $N$-ethyl-2-bromobenzylamine], a neurotoxin that removes the noradrenergic innervation of the cortex. We found that NA depletion reduces the expression of $\sim 20 \%$ of known wakefulness-related transcripts. Most of these transcripts are involved in synaptic plasticity and in the cellular response to stress. In contrast, NA depletion increased the expression of the sleep-related gene encoding the translation elongation factor 2. These results indicate that the activity of the central NA system during wakefulness modulates neuronal transcription to favor synaptic potentiation and counteract cellular stress, whereas its inactivity during sleep may play a permissive role to enhance brain protein synthesis.
\end{abstract}

Key words: cerebral cortex; DSP-4; neural plasticity; noradrenergic; norepinephrine; sleep deprivation

\section{Introduction}

Wakefulness and sleep show striking differences not only in behavior and neural activity but also in gene expression. We recently found that $\sim 5 \%$ of the transcripts in the cerebral cortex change their expression according to behavioral state, independently of time of day (Cirelli et al., 2004). Moreover, we found that transcripts upregulated during wakefulness and sleep are associated with different cellular processes. Wakefulness-related transcripts code for transcription factors, mitochondrial proteins, heat shock proteins (HSPs), and proteins involved in synaptic potentiation, whereas sleep-related transcripts code for proteins involved in protein synthesis, cholesterol synthesis, membrane trafficking, and synaptic depression. These findings have provided new insights about the functional consequences of wakefulness and sleep at the cellular level (Tononi and Cirelli, 2003; Cirelli et al., 2004). However, the mechanisms underlying such pervasive changes in cortical gene expression are unknown. One possibility is that they are controlled directly by the membrane potential, which in cortical cells is steadily depolarized during waking and undergoes slow oscillations during nonrapid eye movement (NREM) sleep (Steriade et al., 2001). Another possibility is that they result from the action of neuromodulatory systems with diffuse projections whose firing rate is high in wakefulness and low in sleep.

The noradrenergic (NA) neurons of the locus ceruleus (LC) and the serotonergic neurons of the nucleus raphe dorsalis are

Received March 15, 2004; revised April 29, 2004; accepted May 3, 2004.

This work was funded by the National Institute of Mental Health and by the Department of Defense. We thank Drs. Valeri Karlov and Carlos E. Padilla for DBA analysis, Drs. Chris Nizzi and Pat Roseboom for their help with the HPLC analysis, and Anne Luebke and Christina M. Gutierrez for technical assistance.

All correspondence should be addressed to Dr. Chiara Cirelli, Department of Psychiatry, University of Wisconsin, Madison, 6001 Research Park Boulevard, Madison, WI 53719. E-mail: ccirelli@wisc.edu.

DOI:10.1523/JNEUROSCI.0949-04.2004

Copyright $\odot 2004$ Society for Neuroscience $\quad$ 0270-6474/04/245410-10\$15.00/0 tonically active during wakefulness, reduce their firing rate during NREM sleep, and cease firing during rapid eye movement (REM) sleep (Hobson et al., 1975; McGinty and Harper, 1976; Aston-Jones and Bloom, 1981a). Moreover, the firing rate of LC neurons, but not that of raphe dorsalis neurons, increases phasically in response to salient events (Aston-Jones and Bloom, 1981b; Rasmussen et al., 1986) and in relation to the decision to act (Clayton et al., 2003). We demonstrated previously that an intact LC is required for the high expression during wakefulness of five genes involved in synaptic plasticity (Cirelli et al., 1996; Cirelli and Tononi, 2000b). Specifically, after producing a lesion of LC with the neurotoxin DSP-4 [N-(2-chloroethyl)- $N$-ethyl-2bromobenzylamine] (Fritschy and Grzanna, 1989), we found that the cortical expression of Arc, BDNF, c-fos, nerve growth factor inducible-A (NGFI-A), and phosphorylated cAMP response element-binding protein during wakefulness was decreased and often as low as during sleep. In contrast, a neurotoxic lesion of the serotonergic system had no effect on the expression of these genes (Tononi et al., 2000).

However, does LC control the expression of other wakefulness-related or sleep-related transcripts? If so, what are the genes, and what are their functions? In this study, we measured the expression of $\sim 5000$ transcripts in the cerebral cortex of normal rats and of rats pretreated with DSP-4. Taking advantage of our database of gene expression changes associated with wakefulness and sleep (Cirelli et al., 2004), we then performed a conjunction search to determine which state-dependent genes are sensitive to noradrenergic depletion. We found that NA positively modulates the expression of $\sim 20 \%$ of all known wakefulness-related transcripts. Most of these transcripts are involved in synaptic plasticity and in the cellular response to stress. In contrast, the sleep-related transcript for the translation elongation factor 2 (EF2) was the only known transcript whose expression increased after cortical NA depletion. Thus, LC activity 
during wakefulness modulates neuronal transcription to favor synaptic potentiation and memory acquisition and to counteract cellular stress, whereas LC inactivity during sleep may play a permissive role to enhance brain protein synthesis.

\section{Materials and Methods}

Animal groups and sleep recording. Male inbred Wistar-Kyoto (WKY) rats were pretreated with the selective serotonin (5-HT) uptake inhibitor fluoxetine $(10 \mathrm{mg} / \mathrm{kg}$, i.p.) to minimize the effects of DSP-4 on serotoninergic terminals and were injected 30 min later with either saline or DSP-4 (50 mg/kg, i.p.; Research Biochemicals, Natick, MA) (see below). One week later, under pentobarbital anesthesia $(60-75 \mathrm{mg} / \mathrm{kg}$, i.p.), rats were implanted with screw electrodes on the dura over the frontal, parietal, and occipital cortex to record the electroencephalogram (EEG) and with silver electrodes in the neck muscles of both sides to record the electromyogram. After surgery, rats were housed individually in sound-proof recording cages where lighting and temperature were kept constant (12 hr light/dark cycle, lights on at 10:00 A.M.; $24 \pm 1^{\circ} \mathrm{C}$; food and water available ad libitum). Immediately after recovery from anesthesia, rats were connected via a flexible cable and a commutator (Airflyte, Bayonne, NJ) to a Grass electroencephalograph (model 15LT; Astro-Med, West Warwick, RI) and recorded continuously for 1-2 weeks. Each day from 10:00 to 10:30 A.M., all rats were gently handled and exposed to a new object to become familiar with the sleep deprivation procedure. Salinetreated and DSP-4-treated rats were killed at 6:00 P.M. after being kept awake for $8 \mathrm{hr}$ by introducing novel objects in their cages. Every new object was delivered just after the first signs of synchronization in the EEG signal. This intervention triggered exploratory behavior in all animals. Animal protocols followed the National Institutes of Health Guide for the Care and Use of Laboratory Animals and were in accordance with institutional guidelines.

Lesions of the noradrenergic system. To lesion the NA system, we used injections of the neurotoxin DSP-4. Lesions of the central noradrenergic system need to be selective, leaving other aminergic systems intact. Moreover, it is important that only the central noradrenergic system be affected to avoid confounding factors caused by the involvement of the peripheral nervous system. Injections of two neurotoxins, DSP-4 and 6-hydroxydopamine (6-OHDA), represent the methods of choice for selective central noradrenergic lesions. 6-OHDA does not cross the blood-brain barrier and therefore must be infused directly into the brain. The intracerebroventricular injection of 6-OHDA causes a rapid and long-lasting depletion of brain noradrenaline (Bloom, 1971), but the dopaminergic system is also affected (Hedreen and Chalmers, 1972) so that a selective depletion of cortical NA fibers can only be achieved by 6-OHDA injections in the dorsal noradrenergic bundle (Robbins and Everitt, 1995). In contrast, DSP-4 can be given intraperitoneally. DSP-4 is a site-directed alkylating agent with an affinity for the neuronal uptake transporter (Dudley et al., 1990). It accumulates within the nerve endings and appears to deplete catecholamines by affecting their transport, possibly by reducing mitochondrial function. As confirmed in this study, when given with fluoxetine, which protects serotonergic fibers, DSP-4 can act as a selective neurotoxin for NA neurons, with little effect on the serotonergic system and no effect on the dopaminergic system. However, DSP-4 has some potential limitations. A few weeks after DSP-4 treatment, damaged NA fibers are capable of restoring some of their lost functions (Fritschy and Grzanna, 1992). Moreover, DSP-4 affects the vast majority of noradrenergic fibers, which originate in the LC, but not the small percentage of fibers originating in cell groups A1 and A2 (Fritschy and Grzanna, 1989). Finally, the efficacy of the DSP-4 lesion can vary from animal to animal, and an incomplete lesion (NA depletion of $<80 \%$ ) can cause "paradoxical" effects resulting from compensatory mechanisms, such as the upregulation of adrenergic receptors (Robbins and Everitt, 1995). To overcome these limitations, all animals in this study were killed within the second or third week after DSP-4 treatment, and HPLC measurements were used to confirm that cortical NA levels were reduced by at least $80 \%$ compared with control animals.

Assay of NA, dopamine, 5-HT, and metabolites. Rats were deeply anesthetized with isoflurane (within $2 \mathrm{~min}$ ) and decapitated. The heads were cooled in liquid nitrogen, and the whole brains were rapidly removed and placed on ice. Cerebral cortex, hippocampus, and cerebellum were dissected out and frozen immediately by immersion of the tubes in liquid nitrogen. All samples were stored at $-80^{\circ} \mathrm{C}$ until the time of the assay. Levels of NA, dopamine (DA), and its metabolites 3,4-dihydroxyphenylacetic acid (DOPAC) and homovanillic acid (HVA), and 5-HT and its metabolite 5-hydroxyindoleacetic acid (5-HIAA) were measured in the left cerebral cortex using HPLC with electrochemical detection, using the method described by Fuertes et al. (2000). Briefly, the left cerebral cortex from each rat was homogenized in $0.02 \mathrm{M}$ perchloric acid using a motor-driven PotterElvehjem homogenizer. After centrifugation at $13,000 \mathrm{rpm}$ for $5 \mathrm{~min}$ at $4^{\circ} \mathrm{C}$, the clear supernatant was filtered through a $0.22 \mu \mathrm{m}$ Millex GP Filter Unit (Millipore, Bedford, MA), and $15 \mu \mathrm{l}$ were injected into a $3 \mu \mathrm{m}$ C18 reversephase column (ESA, Chelmsford, MA) in an HPLC system (ESA) in which NA, DA, and 5-HT and metabolites were analyzed. The mobile phase consisted of $0.1 \mathrm{~m}$ sodium phosphate, $50 \mathrm{~mm}$ citric acid, $1.8 \mathrm{~mm} 1$-octanesulfonic acid, and $10 \%$ acetonitrile, adjusted to $\mathrm{pH} 3.01$, and the flow rate was 0.5 $\mathrm{ml} / \mathrm{min}$. Values were expressed as nanograms per milliliter of tissue homogenate, on the basis of internal standard measurements using dihydroxybenzylamine. The nonparametric Mann-Whitney $U$ test was used for the statistical analysis of the results.

$m R N A$ differential display. The study was performed on six salinetreated rats and six DSP-4-treated rats, none of which were used for microarray analysis. mRNA differential display was performed as described previously (Cirelli and Tononi, 1998, 2000a). Briefly, total RNA $(2 \mu \mathrm{g})$ from the right cerebral cortex of each animal was individually reverse transcribed using Superscript II reverse transcriptase (Invitrogen, Gaithersburg, MD) and one of three 3' composite anchor primers $\mathrm{E}_{1 \mathrm{~T}}{ }_{12} \mathrm{M}$ (E1, 5'CGGAATTCGG; M is A, C, or G). Each reverse transcription reaction was then amplified by PCR in the presence of $\left[\alpha^{-}{ }^{33} \mathrm{P}\right] \mathrm{dATP}$ (DuPont NEN, Natick, MA). The primers used were one of the three $3^{\prime}$ anchor primers used for the reverse transcription and one of thirty-five E2-AP 5' arbitrary primers, in which E2 is CGTGAATTCG and AP is a sequence of $10 \mathrm{bp}$ with a presence of $50 \% \mathrm{G}+\mathrm{C}$ and $\mathrm{A}+\mathrm{T}$ and an absence of uninterrupted self-complementarity of more than two nucleotides. PCR conditions were as described previously. Radiolabeled PCR products were separated on $6 \%$ denaturating polyacrylamide gels and visualized by autoradiography. PCR reactions were performed in duplicate for each individual animal and run in parallel in the same gel. Differentially expressed bands were quantified with a PhosphorImager (Amersham Biosciences, Piscataway, NJ) by measuring the average volume of each band for each lane and subtracting the background. The mean density within and among conditions was calculated, and significant differences among conditions were evaluated by ANOVA, followed by Bonferroni correction. Differentially expressed bands were recovered from dried gels, reamplified by PCR using the same primers, and subcloned into pCRII vectors using the TA cloning kit (Invitrogen, Carlsbad, CA). Plasmid DNA sequencing of cloned cDNAs was performed using the Cy5 AutoRead sequencing kit (Amersham Biosciences, Uppsala, Sweden). Sequences were screened using the BLAST program (basic local alignment search tool program) and the European Molecular Biology Laboratory and GenBank databases.

Microarrays: labeling, hybridization, and data analysis. Microarray analysis was performed on pooled RNA from seven saline-treated rats and seven DSP-4-treated rats, whereas subsequent real-time quantitative PCR ( $\mathrm{qPCR}$ ) was performed both on pooled RNA from the same animals (technical verification) and on pooled RNA from independent groups of four saline-treated and four DSP-4-treated rats (biological verification). Total RNA was isolated from the right cerebral cortex of each animal by using Trizol (Invitrogen, Gaithersburg, MD), according to the instructions of the manufacturer. Final RNA concentrations were determined spectrophotometrically. An equal mass amount of total RNA from the cerebral cortex of each animal was pooled from seven rats within each experimental group $(20 \mu \mathrm{g} / \mathrm{pool})$ and converted into first-strand cDNA using Superscript II Rnase $\mathrm{H}^{-}$reverse transcriptase (Invitrogen, Carlsbad, CA), and the second strand was synthesized, all according to the Affymetrix Gene Expression manual (Affymetrix, Santa Clara, CA). cDNA was then converted to biotinylated cRNA using the ENZO BioArray High Yield In Vitro Transcription kit (Enzo Life Sciences, Farming- 
dale, NY), according to the instructions of the manufacturer. The cRNA was fragmented at $0.5 \mu \mathrm{g} / \mu \mathrm{l}$ final concentration in $1 \times$ fragmentation buffer ( $40 \mathrm{~mm}$ Tris-acetate, $\mathrm{pH} 8.1,100 \mathrm{~mm}$ potassium acetate, and 30 mM magnesium acetate). The size range of cRNA before $(0.5 \mathrm{~kb}$ and longer) and after (35-200 base fragments) fragmentation was checked by denaturing agarose electrophoresis. The hybridization reaction and the automated hybridization procedure were performed according to the Affymetrix instructions. Briefly, the procedure involved a $16 \mathrm{hr}$ hybridization, followed by two washes and staining with streptavidin-phycoerythrin (SAPE) (Affymetrix) stain solution. The staining was followed by another wash, antibody amplification with biotinylated antibody, a second SAPE staining, and a final wash (Affymetrix GeneChip Expression Analysis Technical Manual). Each sample was hybridized to an Affymetrix GeneChip U34A, scanned, and normalized according to the Affymetrix GeneChip Expression Analysis Technical Manual. Quality of the cDNA and cRNA syntheses was determined by the $3^{\prime} / 5^{\prime}$ ratio of housekeeping genes within the array (ubiquitin, glyceraldehyde 3 -phosphate dehydrogenase, $\beta$-actin, and hexokinase). For each cDNA represented in the array, a ratio of intensities and its statistical significance were calculated. Statistical analysis was performed using paired nonparametric tests (MicroArray Suite 5.0; Affymetrix) (Bolstad et al., 2003). Statistical analysis was also performed using a Discrete Bayesian Approach (DBA) [SBI-Moldyn, San Diego, CA; Karlov VI, Padilla CE, Maggio E, Billingsley F, Kasten B (2002) U.S. Patent application 20030065535]. DBA, which is based on Bayesian nonlinear statistical analysis and extensive Monte Carlo cross-validation, confirmed $>90 \%$ of the NA-modulated genes identified by MicroArray Suite 5.0.

Real-time $q P C R$. Real-time qPCR was performed as described previously (Cirelli and Tononi, 2000a) (Sequence Detection System 5700; PerkinElmer Life Sciences, Wellesley, MA). Briefly, reverse transcription reactions were performed in parallel on DNase I-digested pooled total RNA from saline-treated and DSP-4-treated rats. Before reverse transcription, total RNA was confirmed to be free of contaminating DNA sequences by PCR using rat $\beta$-actin-specific primer pairs designed to differentiate between cDNA, genomic DNA, and pseudogene genomic DNA. Eight reverse transcription reactions were performed for each experimental group. Reverse transcription reactions were as follows: $100 \mathrm{ng}$ of total RNA, $2.5 \mu$ l of oligo-dT 16 ( $500 \mu \mathrm{g} / \mathrm{ml}), 5 \mu \mathrm{l}$ of deoxynucleoside triphosphate (dNTP) mix (10 mM each dNTP), and $1 \mathrm{pg}$ of artificial transcript (Integrated DNA Technologies, Coralville, IA), with $\mathrm{H}_{2} \mathrm{O}$ to $29.75 \mu \mathrm{l}$. Samples were incubated at $70^{\circ} \mathrm{C}$ for $10 \mathrm{~min}$, put briefly on ice, and then incubated at $42^{\circ} \mathrm{C}$ for $2-5 \mathrm{~min}$. Mix $2(10 \mu \mathrm{l}$ of $5 \times$ Superscript II First Strand Buffer, $5 \mu \mathrm{l}$ of $0.1 \mathrm{M}$ DTT, $4 \mu \mathrm{l}$ of $25 \mathrm{mM} \mathrm{MgCl}_{2}$, and 1.25 $\mu \mathrm{l}$ of Superscript II RNase $\mathrm{H}^{-}$Reverse Transcriptase, $200 \mathrm{U} / \mu \mathrm{l}$ ) was added and mixed, and samples were immediately returned to incubate at $42^{\circ} \mathrm{C}$ for $1 \mathrm{hr}$. Reactions were stopped by incubation at $70^{\circ} \mathrm{C}$ for $15 \mathrm{~min}$. PCR reactions to measure levels of artificial transcript were done to confirm uniformity of reverse transcription within sample groups and between samples. Comparable reverse transcription reactions within a sample group were pooled. Each PCR reaction contained specific forward and reverse primers (200-750 nM final concentration), $2 \times$ SYBR Green Master Mix (used at 3.2×; Applied Biosystems, Warrington, UK), $5 \mu \mathrm{l}$ of a 1:10 dilution of pooled reverse transcription product, and $\mathrm{H}_{2} \mathrm{O}$ to a total volume of $25 \mu \mathrm{l}$. A two-step PCR profile was used as follows: 10 min at $95^{\circ} \mathrm{C}$ denaturation and Amplitaq Gold (Applied Biosystems, Foster City, CA) activation, followed by 40 cycles that alternated between $95^{\circ} \mathrm{C}$ for $15 \mathrm{sec}$ and $60^{\circ} \mathrm{C}$ for $60 \mathrm{sec}$. Dilution series $(1: 2,1: 10,1: 50,1: 250$, and 1:1250) standard curves were performed in quadruplicate for each primer pair using reverse transcription products from generic rat brain total RNA. PCR was done in quintuplicate for each sample condition assayed, and relative quantities were determined based on the equation of the line of best fit derived from the standard curve $\left(R^{2} \geq 0.985\right)$.

\section{Results}

All animals recovered overnight from the DSP-4 injection and increased their body weight during the 3 weeks after the treatment. All rats were recorded continuously for several days after adaptation to the recording environment to establish baseline

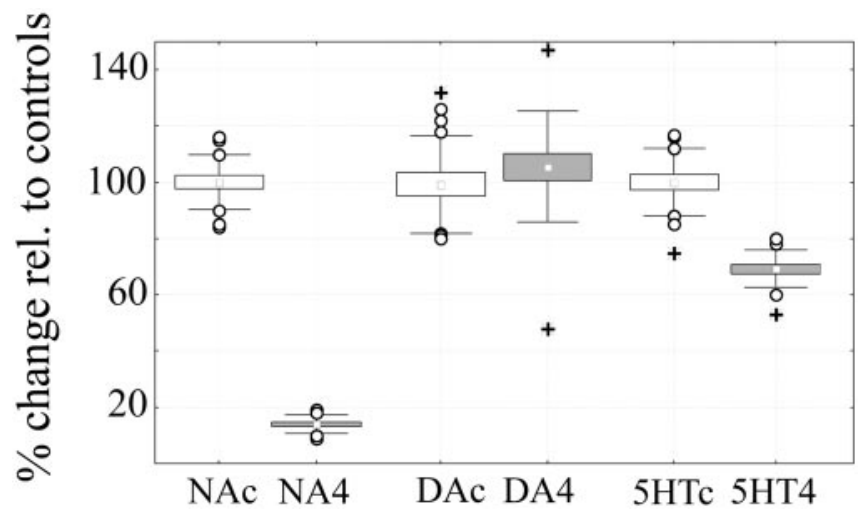

Figure 1. Levels of NA, DA, and 5-HT were measured in the left cerebral cortex of salinetreated controls ( $c$, white boxes) and DSP-4 treated rats ( 4 , gray boxes) using HPLC with electrochemical detection. Values (mean \pm SEM) in DSP-4-treated rats are expressed as percentage relative to saline-treated controls (equivalent to 100\%). NA, $14.2 \pm 1.3 ; \mathrm{DA}, 105.5 \pm 10.3$; $5-H T, 70.3 \pm 5.7$. Boxes equal mean \pm SEM; error bars indicate mean \pm SD; open circles, outliers; plus signs, extremes. Values refer to all experimental animals, including 17 controls (6 for mRNA differential display, 7 for microarrays analysis, and 4 for confirmation experiments) and 17 DSP-4-treated rats ( 6 for mRNA differential display, 7 for microarrays analysis, and 4 for confirmation experiments). Mann-Whitney $U$ test: NA, ${ }^{*} p=0.0017 ; \mathrm{DA}, p=0.277 ; 5-\mathrm{HT}$, ${ }^{*} p=0.0017$. Levels of metabolites DOPAC, HVA, and 5-HIAA were also measured and were as follows (data not shown): DOPAC, $84.4 \pm 9.0(p=0.337) ; H V A, 84.6 \pm 9.2(p=0.11) ; H I A A$, $87.6 \pm 4.6(p=0.14)$.

percentages and distributions of wakefulness, NREM sleep, and REM sleep. On the last day of the experiment, all animals had been kept awake from 10:00 A.M. to 6:00 P.M., except for short $(<30 \mathrm{sec})$ episodes of NREM sleep that could not be avoided at the end of the $8 \mathrm{hr}$ period of exposure to novel objects.

\section{Effects of DSP-4 treatment on brain monoamine levels}

Figure 1 shows that, in agreement with previous work (Dudley et al., 1990), DSP-4 lesions were effective and quite selective for NA. Cortical NA levels were reduced by $>85 \%$ in all DSP-4-treated animals relative to saline-treated controls. In contrast, 5-HT content was only slightly reduced, and DA levels were preserved.

\section{Effects of DSP-4 treatment on behavioral states}

All rats were asleep for most of the light period and awake for most of the dark period, as expected under a $12 \mathrm{hr}$ light/dark schedule. As in previous studies (Cirelli et al., 1996; Cirelli and Tononi, 2000b), overall daily percentages of behavioral states 2-3 weeks after the DSP-4 injection did not differ between salinetreated and DSP-4-treated animals (Fig. 2). Also in agreement with previous reports (Cirelli et al., 1996; Cirelli and Tononi, 2000b), overall EEG power did not differ between the two experimental groups in any frequency bin (data not shown).

\section{mRNA differential display}

In an initial set of experiments, we used mRNA differential display to evaluate differences in gene expression among individual animals. One hundred five primer combinations were used, for a total of 105 gels. As in previous studies (Cirelli and Tononi, 1998, $2000 \mathrm{a}$ ), the mean number of PCR products visualized in each gel was at least 50, thus theoretically allowing the evaluation of $>5000$ RNA species. The band patterns obtained in separate experiments using the same primers were highly reproducible, whereas patterns were markedly different when different primer pairs were used. As in previous studies (Cirelli and Tononi, 1998, 2000a), the vast majority of bands were similarly expressed in all 


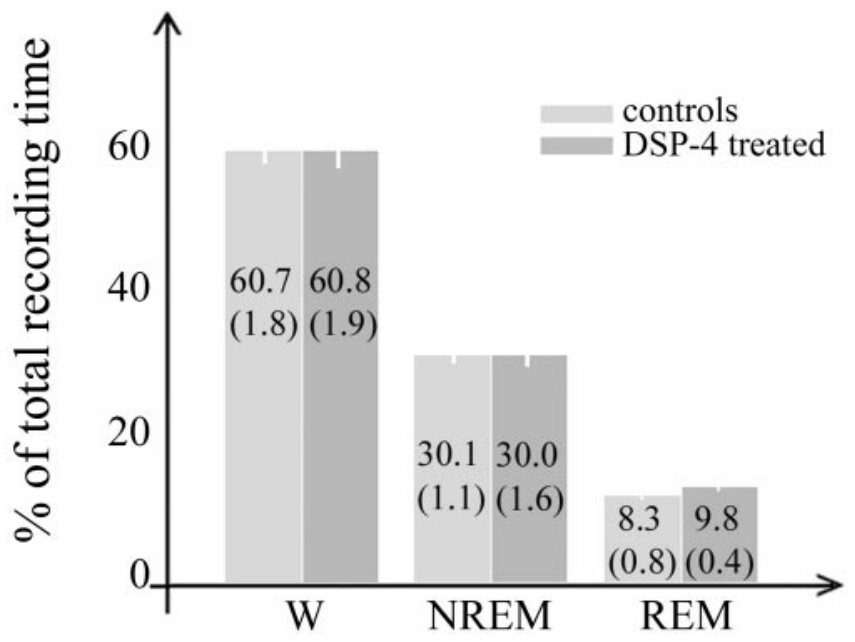

Figure 2. Wakefulness (W), NREM, and REM sleep in saline-treated (controls; $n=17$ ) and DSP-4 treated $(n=17)$ rats. Values refer to the $24 \mathrm{hr}$ period preceding the final experimental day and are expressed as percentage of total recording time (mean \pm SEM in parenthesis; Mann-Whitney $U$ test: $W, p=0.72$; NREM, $p=0.67$; REM, $p=0.08$ ).
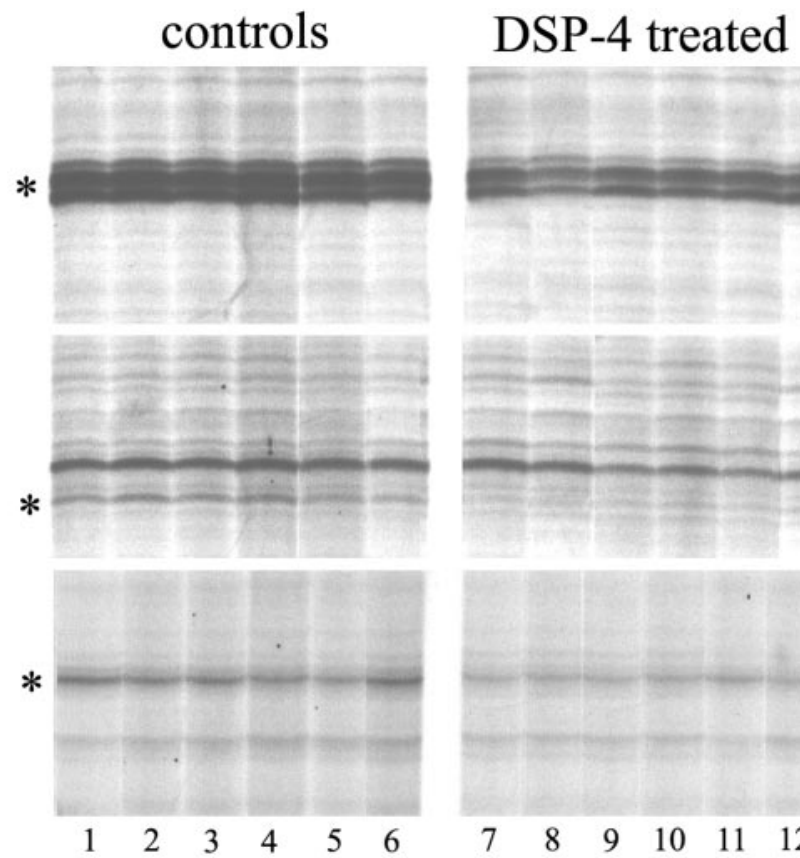

Figure 3. Examples of mRNA differential display analysis of cerebral cortex RNA in saline-treated (controls, lanes 1-6) and DSP-4 treated (lanes 7-12) rats. Each lane corresponds to a single rat. The figure shows a small section of three different gels. The band indicated by an asterisk in the two upper gels corresponds to NGFI-A (each gel used a different sets of primers), and the band indicated by an asterisk on the lower gel corresponds to minoxidil(aryl)sulfotransferase.

individual animals and in both conditions, indicating that interindividual variability in these inbred strains is low. Visual inspection identified 12 bands that were differentially expressed between conditions, all with higher expression in saline-treated rats (Fig. 3). All bands were excised from the gel, reamplified, cloned, and sequenced. Partial DNA sequence analysis revealed flanking sites complementary to the PCR primers in all cases, and all transcripts were 200-700 bp in size. Three transcripts corresponded to expressed sequence tags (ESTs). The remaining bands with higher expression levels in saline-treated animals corresponded to eight known genes coding for $\alpha$-crystallin B, Arc, aryl sulfo- transferase, BDNF, immunoglobulin binding protein (BiP), c-Fos, HSP70, and NGFI-A. NGFI-A was isolated twice using two different sets of primers. Thus, this screening identified at least eight known genes whose expression is positively modulated by NA. For four of them, $A r c, B D N F$, c-fos, and NGFI-A, the current results confirm previous findings obtained using a combination of ribonuclease protection assays, in situ hybridization, and cDNA microarrays (Cirelli et al., 1996, 2000b).

\section{cDNA microarrays}

In a second set of experiments, performed on an independent group of animals, we used cDNA microarrays to comprehensively evaluate gene expression changes between conditions. To properly compare the effects of NA depletion with statedependent gene expression, microarray hybridization and analysis were performed exactly as in our recent study of gene expression in sleep and wakefulness (Cirelli et al., 2004). Briefly, total RNA from the cerebral cortex of seven saline-treated and seven DSP-4-treated rats was analyzed using Affymetrix high-density oligonucleotide arrays (Rat GeneChip RGU34A) to screen for the expression of $\sim 7000$ annotated sequences and 1000 ESTs. The analysis was performed using a set of statistical and empirical parameters aimed at minimizing the number of differentially expressed transcripts while maximizing the number of positive controls (see Materials and Methods). Transcripts whose expression level was too low in both saline-treated and DSP-4-treated rats were called "absent" and removed from the analysis (among these were the transcripts coding for most adrenergic receptors). Approximately $62 \%$ of the transcripts remained after this step (4978 of 8000 ). Thus, although extensive, this screening is not exhaustive, because it covers approximately one-fifth of the rat genome (Gibbs et al., 2004). To limit technical variability, we pooled RNA from seven animals for each experimental group and performed three independent replicas of all the steps of the experiment, from first-strand cDNA synthesis to chip hybridization. As in our previous study (Cirelli et al., 2004), outlier effects are unlikely because of the use of pooled RNA from a homogeneous tissue (whole cerebral cortex) and because of the choice of inbred WKY rats, fully adapted to the recording environment and carefully selected for behavioral state (see Materials and Methods). Most importantly, the results obtained with mRNA differential display indicate that inter-individual differences in cortical gene expression patterns among animals belonging to the same group are minimal.

Significant expression changes were determined with paired nonparametric tests (MicroArray Suite 5.0; Affymetrix) (Bolstad et al., 2003). Transcripts whose expression was considered upregulated or downregulated after DSP-4 treatment had to be called "increased" or "decreased," respectively, in at least two of three nonparametric statistical comparisons between controls and DSP-4 groups. A technique called Discrete Bayesian Approach (SBI-Moldyn) was also used as an independent method for the identification of differentially expressed transcripts. DBA, which is based on Bayesian nonlinear statistical analysis and extensive Monte Carlo cross-validation, confirmed $>90 \%$ of the transcripts identified by MicroArray Suite 5.0.

To validate microarray results, we first examined positive controls, defined as transcripts that had been identified as NAdependent in different sets of animals in either previous reports (Cirelli et al., 1998, 2000b) or this study, using mRNA differential display. Of eight previously identified positive controls (the genes coding for $\alpha$-crystallin B, Arc, arylsulfotransferase, BDNF, BiP, c-Fos, HSP70, and NGFI-A), seven (all except BDNF) were rep- 
Table 1

Decreased with DSP-4 (up with NA) GBA\#

AB003726 Vesl (EVHI domain, in all homer isoforms) AB017140 PSD-Zip45 (Homerlc, Vesl-1L) AF085693 GIT1

AF097593 N-cadherin

A1030286 brain derived neurotrophic factor (BDNF)* Al171462 heat stable antigen CD24

All 76308 CDC42

D64045 phosphatidylinositol 3-kinase p85 alpha subunit D85183 SHPS-1

U75397 nerve growth factor-induced (NGFI-A)

$\$ 49491$ proenkephalin

S82649 Narp, neuronal activity-regulated pentraxin

U19866 Arc (Arg3.1)*

X06769 c-fos*

AB005540 Cdc2-related kinases PCTAIRE2

$\mathrm{AB} 019145$ regulator of G-protein signaling 9 (RGS9)

AF030089 ania-4

AII 76710 nuclear receptor subfamily 4, group A, n. 3

L13151 GTPase-activating protein (GAP)

M22254 sodium channel II voltage-gated

M26161 voltage-gated potassium channel Kv1.1

M31174 Thyroid hormone receptor alpha (C-erbA-alpha)

M64301 extracellular signal-related kinase (ERK3)

M83298 protein phosphatase 2A 55kD reg. sub. alpha

S55223 14-3-3 protein beta subtype

S56141 sodium-dependent neurotransmitter transporter

S59158 GLAST-1

S61973 NMDA receptor glutamate-binding subunit

U49953 protein kinase MUK2

U67139 PSD-95/SAP90-associated protein-3 (SAPAP3)

U93306 VEGF receptor-2/FLK-1

AA799570 DnaJ (Hsp40) homolog, subfamily A, n. 4

AA848545 programmed cell death 10

AF033027 prenylated SNARE protein Ykt6p

AI010083 peroxiredoxin 1 (Prdxl)

M14050 BiP, glucose-regulated protein GRP78*

M55534 alpha-crystallin B chain *

\$78556 glucose regulated protein grp75

X54793 heat shock protein (hsp60)

AA800250 succinate dehydrogenase complex, subunit A

AF062740 pyruvate dehydrogenase phosphatase 1

Al103396 cytochrome b oxidase (CDK110)

All71355 mitochondrial gene for cytochrome b

L25387 phosphofructokinase C

AA945054 cytochrome b5, microsomal

AF047707 UDP-glucose:ceramide glycosyltransferase

A1228110 UDP-galactose:ceramide galactosyltransferase

AJ011608 DNA polymerase alpha subunit IV (primase)

D89983 ornithine decarboxylase antizyme inhibitor

D10706 ornithine decarboxylase antizyme inhibitor

Al043631 ornithine decarboxylase antizyme inhibitor

L19998 minoxidil sulfotransferase*

U36992 RRU36992 cytochrome P450 Cyp7b1

\section{AA799571 ribosomal protein L35}

AA799735 HS1 binding protein short variant (Hax1)

AA800602 small inducible cytokine subfamily D, ।

AA818858 cyclophilin

AF000899 nucleoporin p58/p45

AF031880 light molecular-weight neurofilament (NF-L)

AF062594 nucleosome assembly protein

All05054 coatomer protein complex, subunit beta I

All 77683 hnRNP protein

D13623 $\mathrm{p} 34$ protein

D45247 proteasome subunit RCX

D90258 proteasome subunit RC8

E03358 polyfunctional protease component $\mathrm{C} 3$

K02248 somatostatin- 14

L13635 growth response protein (HRS)

M99485 myelin/oligodendrocyte glycoprotein (MOG)

U10894 mRNA expressed in carotid artery tissue

U12402 ADP-ribosylation factor-like I (rARL1)

U21718 C426 intestinal epithelium proliferating cell-assoc.

U95052 NAT1

X67859 mRNA for autoantigen
FUNCTIONAL CATEGORY (molecular function/biological process)

\section{PLASTICITY-RELATED}

postsynaptic density protein; links NMDA and metabotropic glutamate receptors to intracellular $\mathrm{Ca}++$ stores

G protein-coupled rec. kinase-interacting protein I; regulator of synapse formation; clustering of AMPA receptors

calcium-dependent cell adhesion molecule

growth factor; neuronal survival, brain plasticity

extracellular glycoprotein; induced during development and neurogenesis; promotion/inhibition of neurite outgrowth

Rho family GTPase; regulation of actin cytoskeleton; activated by cadherin signaling; synaptic plasticity

insertion of AMPA receptors at activated synapses in hippocampal LTP

receptor-type transmembrane glycoprotein; regulates cytoskeletal reorganization and cell-cell communication transcription factor; regulation of transcription, DNA-dependent

proconvulsive opioid peptide; enhances hippocampal induction of LTP

IEG, secreted calcium-dependent lectin; AMPA glutamate receptor clustering

IEG, actin binding, cytoskeleton-associated; acquisition of novel behavior, maintenance phase of LTP

transcription factor; regulation of transcription, DNA-dependent

\section{SIGNAL TRANSDUCTION}

serine/threonine kinase, cyclin-dependent kinase family; regulation of dopamine signaling in the basal ganglia negative regulator of $\mathrm{G}$ protein signaling

activity and neurotransmitter-induced early gene 4 ; dopamine receptor signaling pathway

orphan nuclear receptor

GTPase-activating protein

voltage-gated potassium channel

nonhormone-binding variant, thought to inhibit $\mathrm{T} 3$ action

extracellular signal-regulated kinase

protein serine/threonine phosphatase

binding protein; ubiquitous intracellular regulator; putative protein kinase $\mathrm{C}$ regulatory protein

glial sodium-dependent glutamate transporter; regulation of extracellular glutamate levels

MAPK upstream kinase : activator of the JNK pathway

associates with neurofilaments via the $\mathrm{N}$-terminal region; may link PSD components to neurofilaments

receptor tyrosine kinase; angiogenesis, astroglia proliferation

CELLULAR STRESS RESPONSE

cochaperone of the hsp70 family

soluble $\mathrm{N}$-ethylmaleimide-sensitive fusion protein receptor (SNARE) selectively expressed in brain neurons antioxidant enzyme; reduces hydrogen peroxide; widespread glial expression

endoplasmic reticulum chaperone, heat shock protein; folding, assembly and transport of proteins

cellular small heat shock protein, chaperone; resistance to hyperthermia, ischemia, TNF, hydrogen peroxide mitochondrial member of the hsp70-family

cellular heat shock protein; resistance to hyperthermia and ischemia

ENERGY METABOLISM

protein tyrosine phosphatase; activation of the mitochondrial pyruvate dehydrogenase complex

electron transport and oxidative phosphorylation

glycolysis

LIPID METABOLISM

electron donor for desaturases, microsomal electron transport system; fatty acid biosynthesis synthesis of glycosphingolipids

synthesis of glycosphingolipids; essential for the unperturbed lipid bilayer of the myelin membrane

OTHER ENZYMES

DNA replication

polyamine synthesis

sulfotransferase; transfer of sulfonate groups to biogenic amines and other substrates

oxysterol 7-alpha-hydroxylase; cerebral metabolism of dehydroepiandrosterone

\section{MISCELLANEOUS}

associates with HS1, a target of non-receptor protein tyrosine kinases

cytokine; chemokine receptor binding

nucleocytoplasmic transport

intracellular membrane transpor

$\mathrm{r}+\mathrm{B} 117$ ibosome-binding protein, localized to endoplasmic reticulum membranes proteasome endopeptidase, protein catabolism

ubiquitin-proteasome system

minor component of CNS myelin

translation repressor

\section{W/S SLR $\quad \% \quad \%$}

qPCR

$-55$ 


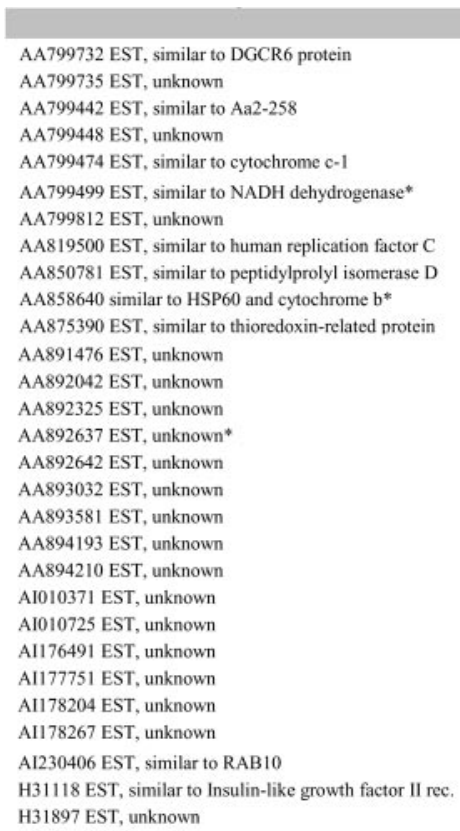

\section{UNKNOWN}

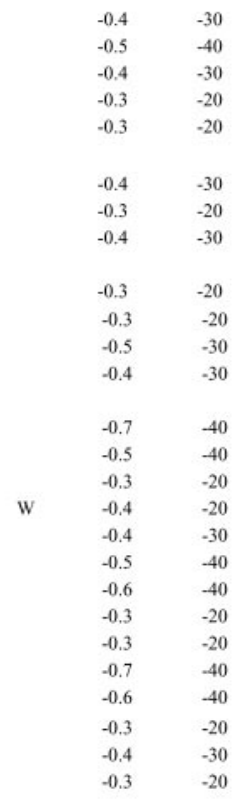

Rat cortical genes exhibiting decreased or increased mRNA levels in DSP-4-treated rats relative to saline-treated animals. For each GenBank accession number (GBA\#), molecular function and biological process annotations were based on an extensive analysis of the literature and, when available, on the gene ontology hierarchy. ${ }^{*}$ indicates gene identified also, or only (in the case of c-fos and BDNF), by mRNA differential display. W, S, Wakefulness-related and sleep-related genes according to Cirelli et al. (2004); SLR, signal-to-log ratio (average); \%, average percentage change as measured by microarray analysis; \% qPCR, average percentage change as measured by quantitative PCR. Note that only two transcripts show increased expression after DSP-4 treatment, including one known gene, EF2.

resented on the chip, one (c-Fos) was called absent, and the expression of five of the remaining six (all except HSP70, whose differential expression also failed to be confirmed with qPCR) was identified as decreased in DSP-4-treated rats by our analysis.

To further validate the microarray results and control for biological variability, we used eight new animals (four salinetreated and four DSP-4-treated rats). qPCR was used to confirm the differential expression of 32 transcripts identified by the microarray analysis as increased in DSP-4 $(n=3)$, decreased in DSP-4 ( $n=25)$, or "no change" $(n=4)$. Altogether, $\sim 81 \%$ (26 of 32 ) of the results of microarray analysis examined were validated by qPCR experiments performed on independent sets of rats. Confirmation rate was $\sim 90 \%$ when the same transcripts were measured by qPCR using pooled RNA from the same sets of animals used in the microarray experiments (technical verification). Thus, on the basis of qPCR results, $<20 \%$ of our selected genes can be ascribed to noise-related biological variability, similar to what has been described in other recent studies (Storch et al., 2002; Cirelli et al., 2004). Because our real-time qPCR had a global absolute error of $<20 \%$, we only report transcripts for which the average percentage change was $>20 \%$ (Table 1 ). As measured by qPCR, expression changes for most NA-dependent transcripts were between 30 and $60 \%$, similar to the range of modulation reported for mammalian transcripts affected by circadian time (Akhtar et al., 2002; Panda et al., 2002; Storch et al., 2002; Ueda et al., 2002) and by behavioral state (Cirelli et al., 2004).

Of the 4978 transcripts called present, 97 (including 70 known transcripts and 27 ESTs) were differentially expressed between
DSP-4-treated rats and saline-treated controls. Table 1 shows that, in almost all cases, mRNA levels were lower in DSP-4treated rats relative to saline-treated controls, with only two transcribed sequences (the gene coding for EF2, the eukaryotic elongation factor 2, and one EST) showing higher mRNA levels in LC-lesioned animals. Most known genes whose expression was decreased by the DSP-4 treatment could be grouped in a few functional categories, including neural plasticity, signal transduction, energy and lipid metabolism, and cellular response to stress.

\section{Overlap between state-dependent transcripts and transcripts affected by DSP-4}

This study of NA-dependent gene expression in the cerebral cortex was specifically designed with the aim of enabling a conjunction analysis with our previous study of state-dependent gene expression (Cirelli et al., 2004). We used rats of the same inbred strain, age, and sex as did Cirelli et al. (2004). Moreover, as in that study, rats were kept awake during the first $8 \mathrm{hr}$ of the light period using exposure to novel objects. Finally, both studies used the same Affymetrix rat chips to profile the whole cerebral cortex and applied the same combination of paired nonparametric and Bayesian-based approaches to perform the statistical analysis. Thus, we were able to cross-reference cortical transcripts whose expression was identified previously as wakefulness-related or sleep-related with transcripts identified in this study and whose expression changes after cortical depletion of NA. For the current study, we used chip RGU34A, which includes the great majority 
(>90\%) of all the known transcripts represented in the Affymetrix set (chips B and C mostly include ESTs).

In our study of state-dependent gene expression (Cirelli et al., 2004), of the $\sim 5000$ known transcripts included in the RGU34A chip and called present in the cerebral cortex, 95 were identified as wakefulness related and 107 as sleep related. By comparing the two analyses, we found that $25 \%$ ( 18 of 72 , including c-fos and BDNF) of all the known transcripts whose expression was affected by DSP-4 had been identified previously as modulated by behavioral state, including 16 wakefulnessrelated and two sleep-related transcripts coding for the proteasome subunit RCX and EF2 (Fig. 4A, Table 1). Interestingly, all 16 wakefulness-related known transcripts decreased their expression after cortical NA depletion, whereas the sleeprelated transcript EF2 was the only known transcript identified by the microarray analysis as increased after DSP-4 treatment. qPCR confirmed a significant increase $(84 \%)$ in EF2 mRNA levels after DSP- 4 treatment. Figure $4 B$ shows that the majority (10 of 16) of the transcripts positively modulated by both wakefulness and cortical NA are involved in neural plasticity and in the cellular response to stress. On the other hand, transcripts modulated by NA represented $\sim 9 \%$ (18 of 202) of all known state-dependent genes and 17\% (16 of 95) of all known wakefulnessrelated genes.

\section{Discussion}

In a previous study, we showed that gene expression in the cerebral cortex is markedly modulated by behavioral state (Cirelli et al., 2004). Specifically, we found that 95 transcripts are expressed at higher levels in wakefulness than in sleep, whereas 107 behave in the opposite manner. In this study, we asked to what extent state-dependent changes in gene expression can be accounted for by the action of neuromodulators that are released in a state-dependent manner. Using the same approach as in our previous report, we compared gene expression profiles in the cerebral cortex of control rats and rats in which cortical NA fibers had been destroyed by DSP-4. We found that NA depletion caused the downregulation of $\sim 20 \%$ ( 16 of 95) of the known wakefulness-related genes in the cerebral cortex, most of which involved in synaptic plasticity and in the cellular response to stress. Other transcripts positively modulated by both NA and wakefulness are involved in the regulation of extracellular glutamate levels (GLAST-1, for glutamate-aspartate transporter 1), in the dopamine receptor signaling pathway (ania-4), in the activation of the mitochondrial pyruvate dehydrogenase complex (pyruvate dehydrogenase phosphatase 1), and in the catabolism of catecholamines [minoxidil(aryl)sulfotransferase]. In contrast, only one gene, coding for the translation
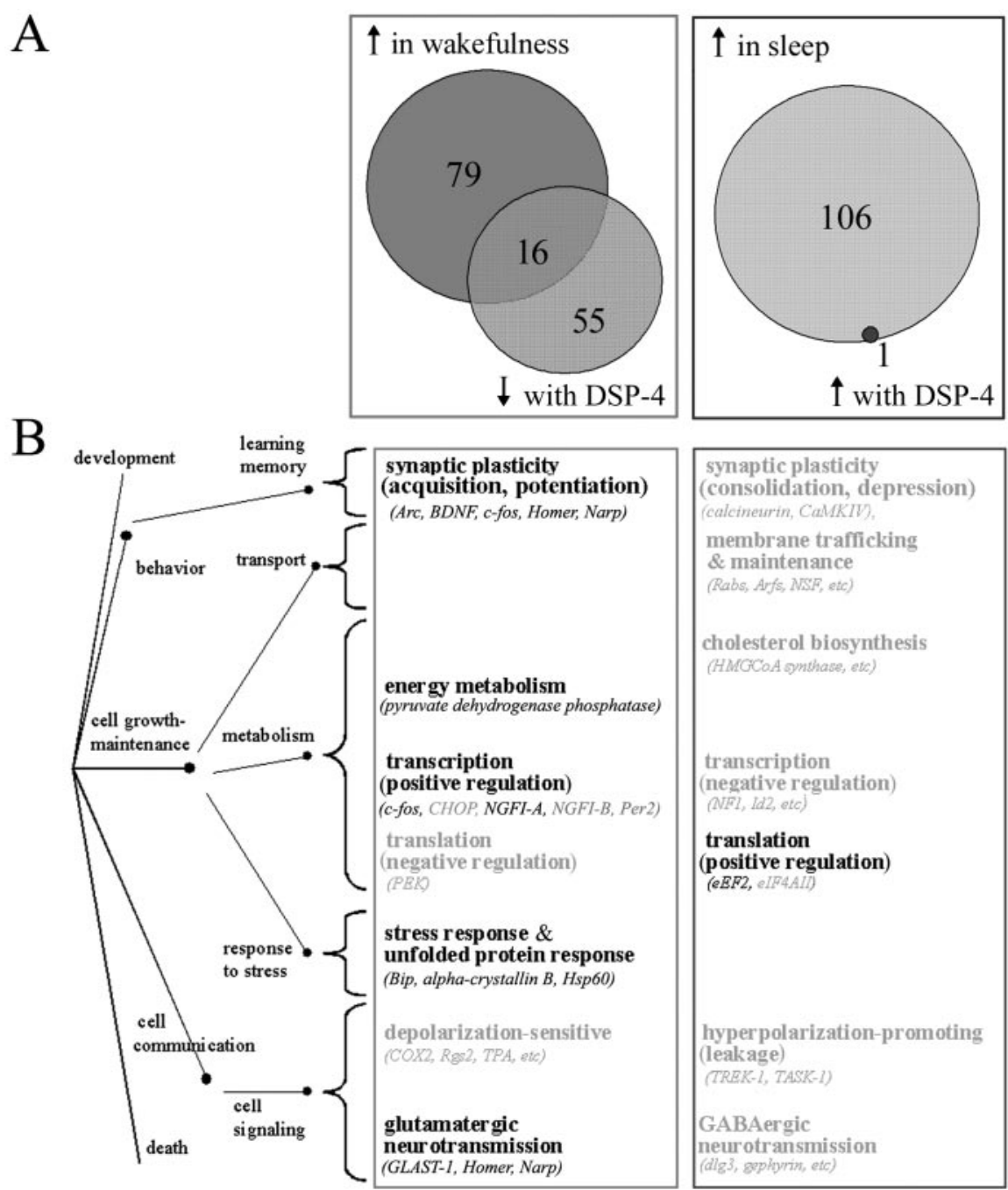

Figure 4. A, Cortical transcripts (GeneChip RGU34A) regulated by sleep and wakefulness, by DSP-4, and their overlap. Numbers only include known genes and not ESTs. $\uparrow$ in wakefulness, Genes whose mRNA levels increased in both spontaneously awake and increased in sleeping animals relative to both spontaneously awake and sleep deprived animals according to Cirelli et al. (2004). $\downarrow$ with DSP-4, Genes whose mRNA levels were decreased in DSP-4 animals (i.e., after cortical NA depletion). $\uparrow$ with DSP-4 wakefulness and with NA include c-fos and BDNF, which were identified using mRNA differential display. The only overlapping (light gray box) and sleep (dark gray box), as by Cirelli et al. (2004). Functional categories listed in bold are those that include one or more transcripts whose expression is also modulated by NA. The tree on the left (dots and connecting paths) represents biological process annotations according to the gene ontology hierarchy.

elongation factor 2 , had been identified previously as sleep related and was one of two that increased their transcript levels after the cortical noradrenergic innervation had been destroyed.

\section{Norepinephrine and plasticity}

The largest functional category of genes whose expression is positively modulated by NA comprises genes involved in neural plasticity. Compelling evidence for a role for NA in plasticity has been obtained both in vitro and in vivo. Studies in vitro have shown that NA enhances the magnitude, duration, and probability of induction of long-term potentiation (LTP) in the cerebral cortex and in the hippocampus, an action mediated primarily via $\beta$ adrenoceptors (Hopkins and Johnson, 1984; Stanton and Sarvey, 1985; Huang and Kandel, 1996; Thomas et al., 1996; Katsuki et al., 1997). Studies in vivo have shown that NA innervation of the 
cortex is needed for ocular dominance plasticity $(\mathrm{Gu}, 2002)$ and other forms of plasticity (Levin et al., 1988). Again, the effect of NA is mainly mediated by $\beta 1$-adrenoceptors, suggesting an LTPrelated effect.

Several transcripts related to plasticity and positively modulated by NA, such as those encoding Arc, N-cadherin, CDC42 (Cell Division Cycle 42), and Homer 1c affect the actin cytoskeleton. Arc interacts with cytoskeletal proteins, and its mRNA localizes to those regions of the dendritic tree that have received synaptic stimulation (Link et al., 1995; Lyford et al., 1995; Steward et al., 1998). Moreover, Arc is specifically induced during the acquisition of a novel behavior (Kelly and Deadwyler, 2002), and the inhibition of Arc expression impairs the maintenance of LTP and the consolidation of long-term memory (Guzowski et al., 2000). The adhesion molecule $\mathrm{N}$-cadherin regulates dendritic spine morphogenesis and is synthesized and recruited to activated synaptic sites during LTP (Huntley et al., 2002). $\mathrm{N}$-cadherin associates with molecules that control cytoskeletal rearrangements, including the Rho family of small GTPases, of which CDC42 is one of the best studied (Huntley et al., 2002). CDC42 activation is required for the dendritic arbor growth driven by enhanced visual activity (Sin et al., 2002). Long isoforms of Homer 1 proteins, such as Homer 1c (also called PSDZip45) provide a physical link between NMDA and metabotropic glutamate receptors (mGluRs), inositol triphosphate receptors, and the TRPC1 (transient receptor potential channel 1) that mediates the replenishment of intracellular calcium stores (Yuan et al., 2003). Homer proteins also regulate the coupling of mGluRs to N-type calcium and M-type potassium channels (Kammermeier et al., 2000). Finally, Homer $1 \mathrm{~b}$ and 1c promote growth and maturation of spines and synapses (Sala et al., 2003), and their overexpression enhances the accumulation of synaptic F-actin and induces synaptic enlargement (Sala et al., 2001; Usui et al., 2003).

Other plasticity-related genes positively modulated by NA, including Narp (neuronal activity-regulated pentraxin), the phosphatidylinositol 3-kinase p $85 \alpha$, and GIT1 (G-proteincoupled receptor kinase-interacting protein 1), regulate the activity and clustering of glutamate AMPA receptors. The activation of AMPA receptors is sufficient to maintain dendritic spines, and their insertion into synapses is essential for the induction and maintenance of LTP (Lamprecht and LeDoux, 2004). Moreover, LTP and long-term depression in vivo are associated with complementary changes in the number and phosphorylation levels of AMPA receptors (Heynen et al., 2000, 2003). Narp is a member of the pentraxin family that localizes specifically to excitatory synapses. Narp transgenic expression increases the number of AMPA receptor clusters, whereas dominant-negative Narp reduces such number (Xu et al., 2003). The phosphatidylinositol 3 -kinase $\mathrm{p} 85 \alpha / \mathrm{p} 110 \alpha$ is required for the insertion of AMPA receptors at activated synapses during LTP (Man et al., 2003). Finally, GIT1, which associates with G-protein-coupled receptors and various focal adhesion molecules (Ko et al., 2003), inhibits the ligand-induced endocytosis of several membrane proteins, including the $\beta 2$-adrenergic receptors (Premont et al., 1998). Moreover, GIT1 interacts with liprin- $\alpha$ and GRIP (glutamate receptor-interacting protein) to facilitate the clustering of AMPA receptors at the surface membrane (Ko et al., 2003).

\section{Norepinephrine and cellular stress}

The increased expression of chaperones and heat shock proteins during spontaneous or forced wakefulness is a consistent finding across flies, rats, and humans (Shaw et al., 2000, 2002; Cirelli et al., 2000a, 2004; Gutierrez et al., 2003; Terao et al., 2003). The present study shows that an intact noradrenergic system is essential for the induction of the brain cellular stress response, suggesting that NA may help to protect the brain against several forms of cellular insult. There is some evidence that NA can maintain the brain in a state refractory to inflammatory activation and, in particular, may limit the expression of potentially damaging $\mathrm{cy}-$ tokines and reactive oxygen species. One study, for instance, observed a decrease in the expression of two endogenous antiinflammatory molecules, I $\kappa \mathrm{B}$ (inhibitor of NF- $\kappa \mathrm{B}$ ) and HSP70, after DSP-4 treatment, suggesting that NA maintains a protective heat shock response (Heneka et al., 2003). Moreover, NA can inhibit lipid peroxidation in vitro (Liu and Mori, 1993) and can promote the survival of dopaminergic neurons by directly reducing oxidant production (Troadec et al., 2001). We showed recently that rats that are sleep deprived for several days show no signs of oxidative damage in either the brain or peripheral tissues (Gopalakrishnan et al., 2004). Ongoing experiments are examining whether this effect requires an intact noradrenergic system.

\section{Norepinephrine and protein synthesis}

Only two transcripts increased their expression when cortical NA levels were depleted. The level of one of them, coding for EF2, increased twofold. We had shown previously that transcript levels of EF2 and the initiation factor 4AII, both key components of the translational machinery, are specifically increased during sleep in the brain but not in peripheral tissues, suggesting that sleep may favor brain protein synthesis (Cirelli et al., 2004). This conclusion is in agreement with previous studies showing that leucine incorporation is higher during NREM sleep relative to waking in both rats and monkeys (Ramm and Smith, 1990; Nakanishi et al., 1997). Thus, it appears that the high levels of NA during wakefulness may inhibit brain protein synthesis, whereas the decreased release of NA during sleep may facilitate it.

\section{Other effects of norepinephrine depletion on gene expression}

Many genes whose levels were reduced after NA depletion did not change their expression between sleep and wakefulness. There are several possible explanations why NA depletion by DSP-4 produces changes in gene expression above and beyond those occurring between sleep and wakefulness in association with changes in LC activity. DSP-4 treatment per se may have caused some of these changes through some toxic effect unrelated to NA depletion. This is unlikely because of the following: (1) some of the changes reported here were also observed after NA depletion caused by local injections of 6-OHDA, a neurotoxin with a different mechanism of action; (2) transcriptional changes after DSP-4 treatment affect only $2 \%$ of cortical genes, ruling out a global impairment of transcription; and (3) DSP-4 does not cause nonspecific cytotoxic effects on brain cells (Dudley et al., 1990; Yamamoto et al., 2001). Finally, except for NA terminals, there is no evidence of synaptic loss in adult animals treated with DSP-4 (Matsukawa et al., 2003).

Another possibility is that DSP-4 also affected other neurotransmitters. However, DSP-4 has no effect on cholinergic transmission (Riekkinen et al., 1992; Yamamoto et al. 2001), and the serotonergic system is unlikely to have contributed to the results. Effects on gene expression have only been described after cortical 5-HT levels were reduced $>80 \%$ (Thiriet et al., 2002), although in our study they decreased only by $\sim 30 \%$. More importantly, we previously found (Tononi et al., 2000) that an almost complete lesion of the serotonergic system did not affect several of the same plasticity-related genes whose cortical expression decreased after 
NA depletion (present study) (Cirelli et al., 1996; Cirelli and Tononi, 2000). Finally, cortical glutamatergic transmission is only slightly reduced after DSP-4 treatment (Yamamoto et al., 2001), and glutamatergic antagonists actually increase, rather than decrease, the expression of BDNF and c-fos (Toronen et al., 2002).

A more likely explanation has to do with the cortical levels of NA during sleep versus after DSP-4 lesions. Although LC activity during NREM sleep is much lower than during wakefulness, it is not zero (Hobson et al., 1975; Aston-Jones and Bloom, 1981a). Thus, although there are no direct measurements of NA cortical levels during NREM sleep, it is plausible that they do not decrease as much as after DSP-4 treatment. Perhaps such low levels can only be reached during REM sleep, which accounts for only $10-$ $20 \%$ of total sleep in rats. Another possible explanation is that the reduced firing of LC cells during sleep lasts for a few hours, whereas NA depletion after DSP-4 is nearly permanent. Indeed, knowing how brain gene expression changes after protracted NA depletion may be relevant when considering the effects of pathological conditions or pharmacological manipulations that interfere chronically with the functioning of the noradrenergic system.

\section{References}

Akhtar RA, Reddy AB, Maywood ES, Clayton JD, King VM, Smith AG, Gant TW, Hastings MH, Kyriacou CP (2002) Circadian cycling of the mouse liver transcriptome, as revealed by cDNA microarray, is driven by the suprachiasmatic nucleus. Curr Biol 12:540-550.

Aston-Jones G, Bloom FE (1981a) Activity of norepinephrine-containing locus coeruleus neurons in behaving rats anticipates fluctuations in the sleep-waking cycle. J Neurosci 1:876-886.

Aston-Jones G, Bloom FE (1981b) Norepinephrine-containing locus coeruleus neurons in behaving rats exhibit pronounced responses to nonnoxious environmental stimuli. J Neurosci 1:887-900.

Bloom FE (1971) Fine structural changes in rat brain after intracisternal injection of 6-hydroxydopamine. In: 6-Hydroxydopamine and catecholamine neurons (Malmfors T, Thoenen H, eds), pp 135-150. Amsterdam: North-Holland.

Bolstad BM, Irizarry RA, Astrand M, Speed TP (2003) A comparison of normalization methods for high density oligonucleotide array data based on variance and bias. Bioinformatics 19:185-193.

Cirelli C, Tononi G (1998) Differences in gene expression between sleep and waking as revealed by mRNA differential display. Mol Brain Res 56:293-305.

Cirelli C, Tononi G (2000a) Gene expression in the brain across the sleepwakefulness cycle. Brain Res 885:303-321.

Cirelli C, Tononi G (2000b) Differential expression of plasticity-related genes in waking and sleep and their regulation by the noradrenergic system. J Neurosci 20:9187-9194.

Cirelli C, Pompeiano M, Tononi G (1996) Neuronal gene expression in the waking state: a role for the locus coeruleus. Science 274:1211-1215.

Cirelli C, Gutierrez CM, Tononi G (2004) Extensive and divergent effects of sleep and wakefulness on brain gene expression. Neuron 41:35-43.

Clayton EC, Rajkowski J, Cohen JD, Aston-Jones G (2003) Decision-related activation of monkey locus coeruleus neurons in a forced choice task. Soc Neurosci Abstr 29: 722.27.

Dudley MW, Howard BD, Cho AK (1990) The interaction of the betahaloethyl benzylamines, xylamine, and DSP- 4 with catecholaminergic neurons. Annu Rev Pharmacol Toxicol 30:387-403.

Fritschy JM, Grzanna R (1989) Immunohistochemical analysis of the neurotoxic effects of DSP-4 identifies two populations of noradrenergic axon terminals. Neuroscience 30:181-197.

Fritschy JM, Grzanna R (1992) Restoration of ascending noradrenergic projections by residual locus coeruleus neurons: compensatory response to neurotoxin-induced cell death in the adult rat brain. J Comp Neurol 321:421-441.

Fuertes G, Laorden ML, Milanes MV (2000) Noradrenergic and dopaminergic activity in the hypothalamic paraventricular nucleus after naloxone-induced morphine withdrawal. Neuroendocrinology 71:60-67.

Gibbs RA, Weinstock GM, Metzker ML, Muzny DM, Sodergren EJ, Scherer S, Scott G, Steffen D, Worley KC, Burch PE, Okwuonu G, Hines S, Lewis L, DeRamo C, Delgado O, Dugan-Rocha S, Miner G, Morgan M, Hawes A, Gill R, et al. (2004) Rat Genome Sequencing Project Consortium. Genome sequence of the Brown Norway rat yields insights into mammalian evolution. Nature 428:493-521.

Gopalakrishnan A, Ji LL, Cirelli C (2004) Oxidative stress and cellular damage after sleep deprivation. Sleep 27:27-34.

Gu Q (2002) Neuromodulatory transmitter systems in the cortex and their role in cortical plasticity. Neuroscience 111:815-835.

Gutierrez C, Gambetti PL, Tononi G, Cirelli C (2003) Molecular correlates of fatal familial insomnia. Sleep 26:A416.

Guzowski JF, Lyford GL, Stevenson GD, Houston FP, McGaugh JL, Worley PF, Barnes CA (2000) Inhibition of activity-dependent Arc protein expression in the rat hippocampus impairs the maintenance of long-term potentiation and the consolidation of long-term memory. J Neurosci 20:3993-4001.

Hedreen JC, Chalmers JP (1972) Neuronal degeneration in rat brain induced by 6-hydroxydopamine: a histological and biochemical study. Brain Res 47:1-36.

Heneka MT, Gavrilyuk V, Landreth GE, O’Banion MK, Weinberg G, Feinstein DL (2003) Noradrenergic depletion increases inflammatory responses in brain: effects on IkappaB and HSP70 expression. J Neurochem 85:387-398.

Heynen AJ, Quinlan EM, Bae DC, Bear MF (2000) Bidirectional, activitydependent regulation of glutamate receptors in the adult hippocampus in vivo. Neuron 28:527-536.

Heynen AJ, Yoon BJ, Liu CH, Chung HJ, Huganir RL, Bear MF (2003) Molecular mechanism for loss of visual cortical responsiveness following brief monocular deprivation. Nat Neurosci 6:854-862.

Hobson JA, McCarley RW, Wyzinski PW (1975) Sleep cycle oscillation: reciprocal discharge by two brainstem neuronal groups. Science 189:55-58.

Hopkins WF, Johnston D (1984) Frequency-dependent noradrenergic modulation of long-term potentiation in the hippocampus. Science 226:350-352.

Huang YY, Kandel ER (1996) Modulation of both the early and the late phase of mossy fiber LTP by the activation of $\beta$-adrenergic receptors. Neuron 16:611-617.

Huntley GW, Gil O, Bozdagi O (2002) The cadherin family of cell adhesion molecules: multiple roles in synaptic plasticity. The Neuroscientist 8:221-233.

Kammermeier PJ, Xiao B, Tu JC, Worley PF, Ikeda SR (2000) Homer proteins regulate coupling of group I metabotropic glutamate receptors to $\mathrm{N}$-type calcium and M-type potassium channels. J Neurosci 20:7238-7245.

Katsuki H, Izumi Y, Zorumski CF (1997) Noradrenergic regulation of synaptic plasticity in the hippocampal CA1 region. J Neurophysiol 77:3013-3020.

Kelly MP, Deadwyler SA (2002) Acquisition of a novel behavior induces higher levels of Arc mRNA than does overtrained performance. Neuroscience 110:617-626.

Ko J, Kim S, Valtschanoff JG, Shin H, Lee JR, Sheng M, Premont RT, Weinberg RJ, Kim E (2003) Interaction between liprin- $\alpha$ and GIT1 is required for AMPA receptor targeting. J Neurosci 23:1667-1677.

Lamprecht R, LeDoux J (2004) Structural plasticity and memory. Nat Rev Neurosci 5:45-54.

Levin BE, Craik RL, Hand PJ (1988) The role of norepinephrine in adult rat somatosensory $(\mathrm{SmI})$ cortical metabolism and plasticity. Brain Res 443:261-271.

Link W, Konietzko U, Kauselmann G, Krug M, Schwanke B, Frey U, Kuhl D (1995) Somatodendritic expression of an immediate early gene is regulated by synaptic activity. Proc Natl Acad Sci USA 92:5734-5738.

Liu J, Mori A (1993) Monoamine metabolism provides an antioxidant defense in the brain against oxidant- and free radical-induced damage. Arch Biochem Biophys 302:118-127.

Lyford GL, Yamagata K, Kaufmann WE, Barnes CA, Sanders LK, Copeland NG, Gilbert DJ, Jenkins NA, Lanahan AA, Worley PF (1995) Arc, a growth factor and activity-regulated gene, encodes a novel cytoskeletonassociated protein that is enriched in neuronal dendrites. Neuron $14: 433-445$. 
Man HY, Wang Q, Lu WY, Ju W, Ahmadian G, Liu L, D'Souza S, Wong TP, Taghibiglou C, Lu J, Becker LE, Pei L, Liu F, Wymann MP, MacDonald JF, Wang YT (2003) Activation of PI3-kinase is required for AMPA receptor insertion during LTP of mEPSCs in cultured hippocampal neurons. Neuron 38:611-624.

Matsukawa M, Nakadate K, Ishihara I, Okado N (2003) Synaptic loss following depletion of noradrenaline and/or serotonin in the rat visual cortex: a quantitative electron microscopic study. Neuroscience 122:627-635.

McGinty DJ, Harper RM (1976) Dorsal raphe neurons: depression of firing during sleep in cats. Brain Res 101:569-575.

Nakanishi H, Sun Y, Nakamura RK, Mori K, Ito M, Suda S, Namba H, Storch FI, Dang TP, Mendelson W, Mishkin M, Kennedy C, Gillin JC, Smith CB, Sokoloff L (1997) Positive correlations between cerebral protein synthesis rates and deep sleep in Macaca mulatta. Eur J Neurosci 9:271-279.

Panda S, Antoch MP, Miller BH, Su AI, Schook AB, Straume M, Schultz PG, Kay SA, Takahashi JS, Hogenesch JB (2002) Coordinated transcription of key pathways in the mouse by the circadian clock. Cell 109:307-320.

Premont RT, Claing A, Vitale N, Freeman JL, Pitcher JA, Patton WA, Moss J, Vaughan M, Lefkowitz RJ (1998) beta2-Adrenergic receptor regulation by GIT1, a G protein-coupled receptor kinase-associated ADP ribosylation factor GTPase-activating protein. Proc Natl Acad Sci USA 95:14082-14087.

Ramm P, Smith CT (1990) Rates of cerebral protein synthesis are linked to slow wave sleep in the rat. Physiol Behav 48:749-753.

Rasmussen K, Morilak DA, Jacobs BL (1986) Single unit activity of locus coeruleus neurons in the freely moving cat. I. During naturalistic behavior and in response to simple and complex stimuli. Brain Res 371:324-334.

Riekkinen Jr P, Riekkinen M, Valjakka A, Riekkinen P, Sirvio J (1992) DSP-4, a noradrenergic neurotoxin, produces more severe biochemical and functional deficits in aged than young rats. Brain Res 570:293-299.

Robbins TW, Everitt BJ (1995) Central noradrenaline neurons and behavior. In: Psychopharmacology: the fourth generation of progress (Bloom FE, Kupfer DJ, eds), pp 363-372. New York: Raven.

Sala C, Piech V, Wilson NR, Passafaro M, Liu G, Sheng M (2001) Regulation of dendritic spine morphology and synaptic function by Shank and Homer. Neuron 31:115-130.

Sala C, Futai K, Yamamoto K, Worley PF, Hayashi Y, Sheng M (2003) Inhibition of dendritic spine morphogenesis and synaptic transmission by activity-inducible protein Homerla. J Neurosci 23:6327-6337.

Shaw PJ, Cirelli C, Greenspan RJ, Tononi G (2000) Correlates of sleep and waking in Drosophila melanogaster. Science 287:1834-1837.

Shaw PJ, Tononi G, Greenspan RJ, Robinson DF (2002) Stress response genes protect against lethal effects of sleep deprivation in Drosophila. Nature 417:287-291.

Sin WC, Haas K, Ruthazer ES, Cline HT (2002) Dendrite growth increased by visual activity requires NMDA receptor and Rho GTPases. Nature 419:475-480

Stanton PK, Sarvey JM (1985) Depletion of norepinephrine, but not serotonin, reduces long-term potentiation in the dentate gyrus of rat hippocampal slices. J Neurosci 5:2169-2176.
Steriade M, Timofeev I, Grenier F (2001) Natural waking and sleep states: a view from inside neocortical neurons. J Neurophysiol 85:1969-1985.

Steward O, Wallace CS, Lyford GL, Worley PF (1998) Synaptic activation causes the mRNA for the IEG Arc to localize selectively near activated postsynaptic sites on dendrites. Neuron 21:741-751.

Storch KF, Lipan O, Leykin I, Viswanathan N, Davis FC, Wong WH, Weitz CJ (2002) Extensive and divergent circadian gene expression in liver and heart. Nature 417:78-83.

Terao A, Steininger TL, Hyder K, Apte-Deshpande A, Ding J, Rishipathak D, Davis RW, Heller HC, Kilduff TS (2003) Differential increase in the expression of heat shock protein family members during sleep deprivation and during sleep. Neuroscience 116:187-200.

Thiriet N, Ladenheim B, McCoy MT, Cadet JL (2002) Analysis of ecstasy (MDMA)-induced transcriptional responses in the rat cortex. FASEB J 16:1887-1894.

Thomas MJ, Moody TD, Makhinson M, O’Dell TJ (1996) Activitydependent beta-adrenergic modulation of low frequency stimulation induced LTP in the hippocampal CA1 region. Neuron 17:475-482.

Tononi G, Cirelli C (2003) Sleep and synaptic homeostasis: a hypothesis. Brain Res Bull 62:143-150.

Tononi G, Cirelli C, Shaw PJ (2000) The molecular correlates of sleep, waking, and sleep deprivation. Human Frontier Workshop VIII, The regulation of sleep, (Borbely AA, Hayaishi O, Seinowski TJ, Altman JS, eds), pp 155-168. Strasbourg, France: HFSP.

Toronen P, Storvik M, Linden AM, Kontkane O, Marvanova M, Lakso M, Castren E, Wong G (2002) Expression profiling to understand actions of NMDA/glutamate receptor antagonists in rat brain. Neurochem Res 27:1209-1220

Troadec JD, Marien M, Darios F, Hartmann A, Ruberg M, Colpaert F, Michel PP (2001) Noradrenaline provides long-term protection to dopaminergic neurons by reducing oxidative stress. J Neurochem 79:200-210.

Ueda HR, Chen W, Adachi A, Wakamatsu H, Hayashi S, Takasugi T, Nagano M, Nakahama K, Suzuki Y, Sugano S, Iino M, Shigeyoshi Y, Hashimoto S (2002) A transcription factor response element for gene expression during circadian night. Nature 418:534-539.

Usui S, Konno D, Hori K, Maruoka H, Okabe S, Fujikado T, Tano Y, Sobue K (2003) Synaptic targeting of PSD-Zip45 (Homer 1c) and its involvement in the synaptic accumulation of F-actin. J Biol Chem 278:10619-10628.

Xu D, Hopf C, Reddy R, Cho RW, Guo L, Lanahan A, Petralia RS, Wenthold RJ, O'Brien RJ, Worley P (2003) Narp and NP1 form heterocomplexes that function in developmental and activity-dependent synaptic plasticity. Neuron 39:513-528.

Yamamoto M, Imamura K, Kobayashi M, Nakadate K, Yokoyama C, Watanabe Y, Yamamoto M, Negi A (2001) N-(2-Chloroethyl)- $N$-ethyl-2bromobenzylamine reduces intracellular calcium response to noradrenaline in rat visual cortex. Neuroscience 107:209-218.

Yuan JP, Kiselyov K, Shin DM, Chen J, Shcheynikov N, Kang SH, Dehoff MH, Schwarz MK, Seeburg PH, Muallem S, Worley PF (2003) Homer binds TRPC family channels and is required for gating of TRPC1 by IP3 receptors. Cell 114:777-789. 